\title{
Paternidade Adolescente e os Cuidados ao Bebê com até Um Ano de Idade
}

\author{
Danielle da Costa Souto \\ Tatiane Cappelari Silveira \\ Meiridiane Domingues de Deus \\ Márcia Elisa Jager \\ Ana Cristina Garcia Dias \\ Universidade Federal de Santa Maria \\ Santa Maria, RS, Brasil
}

\begin{abstract}
RESUMO
Este estudo busca conhecer o engajamento do pai adolescente em práticas de cuidados com a criança. Participaram da pesquisa três adolescentes com até 20 anos. Os instrumentos foram duas entrevistas semiestruturadas sobre: (1) expectativas de cuidados ao bebê e (2) envolvimento paterno. Estas foram aplicadas em dois momentos: aos 40 dias do bebê e no primeiro ano. Utilizou-se delineamento de estudo de caso coletivo, de caráter longitudinal. Os resultados foram discutidos com estudos atuais. Ressalta-se que as práticas de cuidados foram influenciadas por fatores externos, como a necessidade de trabalhar ou estudar das companheiras, a separação conjugal e a oferta de apoio familiar. Ainda, destaca-se a influência de características pessoais do pai e do bebê no engajamento paterno em tais práticas. Concluiu-se que os adolescentes conseguiram se engajar satisfatoriamente com os filhos ao longo do primeiro ano de vida. Entretanto, como limitação do estudo aponta-se o número reduzido de participantes.
\end{abstract}

Palavras-chave: Envolvimento; Pais adolescentes; Relações pai-criança.

\section{ABSTRACT}

Teen Fatherhood and Care to the Baby up to One Year of Age

This study seeks to understand the engagement of adolescent father in practice in child care. Participated in the research three teenagers up to 20 years old. The instruments were two semi-structured interviews on: (1) expectations of care to the child and (2) father involvement. These were applied in two stages: 40 days and baby in the first year. We used study design collective case of longitudinal character. The results were discussed with current studies. It is emphasized that care practices were influenced by external factors such as the need to work or study of partners, conjugal separation and offer family support. Still, there is the influence of personal characteristics of father and baby in father's engagement in such practices. It was concluded that teens were able to successfully engage with their children during the first year of life. However, a limitation of the study points up the limited number of participants.

Keywords: Involvement; Adolescent fathers; Father child relations.

\section{RESUMEN}

Paternidad Adolescente y Cuidado del Bebé Hasta Un Año de Edad

Este estudio busca conocer el compromiso del padre adolescente en la práctica en el cuidado de niños. Participaran en la encuesta tres adolescentes de hasta 20 años. Los instrumentos fueron dos entrevistas semi-estructuradas en: (1) las expectativas de atención al bebe y (2) la participación de los padres. Estos fueron aplicados en dos etapas: a los 40 días del bebé en el primer año. Se utilizó el diseño del estudio caso colectivo de carácter longitudinal. Los resultados fueron discutidos con los estudios actuales. Se hace hincapié en que las prácticas de atención fueron influenciados por factores externos, tales como la necesidad de trabajar o estudiar de los compañeros, la separación matrimonial y ofrecer apoyo a la familia. Aún así, se destaca la influencia de las características personales personales de padre y el bebé en el compromiso paterno en tales prácticas. Se concluyó que los adolescentes fueron capaces de participar con éxito con sus hijos durante el primer año de vida. Sin embargo, una limitación del estudio pone en relevancia el escaso número de participantes.

Palabras clave: Envolvimiento; Padres adolescentes; Relaciones padre-hijo. 
O papel paterno veio se modificando ao longo da história. Cabe lembrar que a participação do pai nem sempre foi percebida como importante para o desenvolvimento da criança. Diversos foram os comportamentos que caracterizaram sua interação na família ao longo do tempo. No modelo patriarcal, o pai era uma figura de autoridade incontestável e não se envolvia na criação e educação dos filhos (Goetz \& Vieira, 2011). Isto mudou na década de 1970, com o surgimento de um novo modelo econômico industrial e a crescente independência feminina (Vieira et al., 2014). Atualmente, espera-se que o pai exerça um papel mais participativo e seja presente na vida das crianças, assumindo funções semelhantes às da mãe. Isso pode ocorrer através do exercício de tarefas de cuidados que ainda estão socialmente vinculadas ao papel materno (Souto, Jager, \& Dias, 2013).

Essa nova expressão do papel masculino aparece como uma transformação importante nas relações parentais da família contemporânea (Staudt \& Wagner, 2008). Na paternidade participativa, o pai se envolve no cotidiano dos filhos, em domínios como a alimentação, higiene, lazer e educação. Ele auxilia a mãe e participa do desenvolvimento da criança. Entretanto, o papel de principal provedor da família é atribuído ainda a ele (Sutter \& Bucher-Maluschke, 2008; Vieira et al., 2014).

Nesse sentido, o exercício da paternidade envolve e proporciona o desenvolvimento de práticas e habilidades de cuidados com a criança (Meincke \& Carraro, 2009). Por isso, ao se pensar na perspectiva da relação pai e filho, Lamb, Pleck, Charnov e Levine (1987) propõem o constructo do envolvimento paterno, dividido em três dimensões: a acessibilidade (presença ou disponibilidade potencial do pai para interagir com a criança), a responsabilidade (papel que o pai desempenha assegurando cuidados e recursos para a criança) e o engajamento.

Neste estudo será destacada, em especial, a última dimensão mencionada. Essa diz respeito à experiência do pai no contato direto com o filho, através do cuidado e outras atividades compartilhadas (brincadeiras). As outras dimensões não serão discutidas, pois não fazem parte do foco deste estudo, que objetiva entender o engajamento de pais adolescentes nas práticas de cuidados (brincadeiras, troca de fraldas, roupas, alimentação, sono) com seus filhos durante o primeiro ano de vida da criança.

Vale ressaltar que o engajamento paterno em adolescentes é discutido em alguns estudos comparativos entre a paternidade na fase adulta e na adolescência (Levandowski \& Piccinini, 2006; Levandowski \& Piccinini, 2002). Os resultados indicam que pais adolescentes suficientemente apoiados familiar e socialmente podem ser tão responsivos ao bebê quanto os pais adultos (Levandowski \& Piccinini, 2002). No que se referem especialmente as expectativas desses pais em relação ao envolvimento em práticas e cuidados, os adolescentes apresentam uma maior tendência que os adultos a se imaginarem desempenhando essas tarefas (Levandowski \& Piccinini, 2006).

Portanto, pode-se inferir que a idade com que se torna pai não é um fator relevante para o envolvimento nos cuidados do bebê, mas sim o quanto estes pais são apoiados e incentivados a realizar tais práticas. No contexto da adolescência, o jovem pai passa por uma série de readaptações biopsicossociais para assumir o novo papel e adentrar o mundo adulto, com todas as responsabilidades inerentes ao mesmo. Esta transição gera muita ansiedade, principalmente devido às mudanças que ocorrem em sua vida, tais como, o ingresso no mercado de trabalho, a assunção de mais responsabilidades e a restrição da vida social. Visto que, a rede de apoio exerce função crucial no acolhimento, no apoio financeiro, emocional e afetivo, como facilitadora do exercício paterno (Carvalho, Merighi, \& Jesus, 2009; Jager \& Dias, 2012; Levandowski \& Piccinini, 2002; Levandowski \& Piccinini, 2006; Nogueira, Martins, Schall, \& Modena, 2011; Sampaio, Villela, \& Oliveira, 2014; Scholl, 2012).

A partir do exposto, observa-se que o pai adolescente pode revelar uma relação cuidadosa com a criança e a vivência da paternidade neste período pode não divergir muito daquela exercida durante a vida adulta. Diante do aumento em suas responsabilidades, os adolescentes podem descobrir satisfação com a condição parental, demonstrar apego afetivo aos filhos e perceber a paternidade como uma experiência positiva (Carvalho, Merighi, \& Jesus, 2009; Sampaio, Villela, \& Oliveira, 2014).

A importância desta pesquisa é justificada pela atenção dada a este público, pais adolescentes, de modo a conhecer a sua opinião sobre esta experiência. Visto que a ênfase dada pela mídia e pela sociedade aos estereótipos negativos pode acabar configurando a paternidade adolescente apenas como algo indesejável e patogênico (Nogueira et al., 2011; Venturini \& Piccinini, 2014). Além disso, ressalta-se que é esperada uma definição dos papéis de cada membro da família nas pesquisas atuais, uma vez que isso só pode ser possível ao lançar-se um olhar diferenciado para o papel do pai (Vieira et al., 2014).

Diante da carência de estudos longitudinais brasileiros que investigam a importância da participação paterna na vida da criança (Vieira et al., 2014), esta 
pesquisa acontece em dois diferentes momentos: aos 40 dias e no primeiro ano. Trata-se de um estudo de caso coletivo (Stake, 1994) de caráter longitudinal (Anstey \& Hofer, 2004) que visa verificar as mudanças ocorridas em relação ao envolvimento do pai adolescente nas práticas de cuidados ao longo deste período de tempo específico. A pesquisa busca identificar também os fatores que podem influenciar positiva ou negativamente tais práticas.

\section{MÉTODO}

\section{Participantes}

Participaram do estudo três pais com até 20 anos de idade selecionados de um grupo de sete pais que fizeram parte do estudo longitudinal "Paternidade adolescente e a relação pai-bebê no primeiro ano de vida da criança” (Jager \& Dias, 2012). Este estudo acompanhou esses pais adolescentes com o objetivo de compreender a vivência da paternidade e o envolvimento paterno em práticas de cuidados com o bebê em três momentos: Fase I (até 40 dias após o nascimento do bebê); Fase II (sexto mês de vida do bebê) e Fase III (um ano de vida da criança). Este estudo foi concluído no primeiro semestre letivo de 2014.

O processo de seleção dos participantes para o estudo longitudinal ocorreu através do preenchimento da ficha de triagem durante o período de Janeiro a Março de 2013 em dois hospitais públicos de uma cidade do interior do Estado do Rio Grande do Sul. Para participar do estudo os pais deveriam, no momento do primeiro contato, ter até 20 anos de idade, ser pai (biológico) pela primeira vez de um bebê saudável, estar em um relacionamento amoroso com a mãe do bebê, pertencer à classe econômica $\mathrm{D}$ ou E (renda familiar até R\$ 1.126,00) (Neri, 2010) e aceitar participar voluntariamente do estudo. A escolha dos três pais para constituir o grupo de participantes deste estudo se deu devido os seguintes critérios: ter oferecido informações completas e ricas em significados (ausência de respostas lacônicas, tais como: "bom"; "mais ou menos"; "não sei explicar"; "normal").

\section{Instrumentos, Delineamento e Procedimentos}

O estudo longitudinal de Jager e Dias (2012) utilizou uma ficha de triagem para identificar os critérios de inclusão dos participantes, uma ficha de dados socioeconômico e cultural para caracterizá-los e três entrevistas semiestruturadas para investigar os objetivos do estudo: (1) paternidade, (2) expectativas de cuidados ao bebê e (3) envolvimento paterno. Estas entrevistas foram aplicadas nas três fases da pesquisa.

Os instrumentos que ofereceram as informações analisadas especialmente neste estudo foram as entrevistas sobre as expectativas de cuidados ao bebê e a entrevista sobre envolvimento paterno. Ambos os instrumentos foram escolhidos tendo em vista o objetivo central desta pesquisa que é investigar como ocorre o envolvimento paterno do adolescente em práticas de cuidados com o bebê ao longo do primeiro ano de vida da criança. A entrevista sobre expectativas de cuidados ao bebê aplicada na Fase I investigou a experiência do pai nos primeiros dias com o bebê; as práticas de cuidados realizadas; e expectativas de práticas de cuidados a serem realizadas com o bebê durante o puerpério (cuidados diretos, indiretos e manifestações de afeto e carinho). A entrevista sobre envolvimento paterno aplicada na Fase III investigou questões sobre as práticas de cuidados diretos e indiretos oferecidos ao bebê e comportamentos de afeto e carinho entre pai e filho no primeiro ano.

Foi utilizado um delineamento de estudo de caso coletivo (Stake, 1994) de caráter longitudinal (Anstey \& Hofer, 2004). Ofereceu-se atenção às particularidades e semelhanças entre os resultados encontrados.

As entrevistas foram aplicadas nos participantes do estudo em dois momentos distintos: no período de até 40 dias após o nascimento do bebê e no primeiro ano de vida da criança (Fase I e Fase III do estudo de Jager e Dias, (2012), respectivamente). A entrevista sobre expectativas de cuidados ao bebê (Fase I) aconteceu em local cedido pelo hospital em dia e hora apropriados ao participante. A entrevista sobre envolvimento paterno (Fase III) aconteceu nas residências dos adolescentes. As entrevistas foram realizadas individualmente e tiveram duração de, em média, uma hora e trinta minutos. Todas as entrevistas foram gravadas, transcritas e, após análise, apagadas na íntegra.

O período de até 40 dias após o nascimento do bebê e o primeiro ano de vida da criança foram escolhidos como recorte para este estudo, pois logo após o nascimento, embora os cuidados já tenham sido iniciados, os pais possuem expectativas sobre como será a relação com o filho. Estas já existiam durante a gravidez, mas o nascimento do bebê parece intensificá-las. Nos meses seguintes ao nascimento, por uma questão de sobrevivência, o bebê precisa de alguém que atenda as suas necessidades biológicas, como por exemplo, sensações de fome, sede e frio e cuide de suas necessidades fisiológicas. Estas práticas de cuidados, quando acompanhadas de um investimento afetivo por parte dos pais, são responsáveis pela 
construção do apego. Assim, os meses seguintes após o nascimento do bebê se constituem como o berço das primeiras relações entre pais e filhos. É principalmente através das práticas de cuidados que os pais realizam com seu bebê que o vínculo afetivo é construído, sendo capaz de influenciar no desenvolvimento físico, psíquico e social da criança (Brazelton \& Cramer, 2002).

Este estudo foi aprovado pelo comitê de ética da Universidade Federal de Santa Maria sob o no de parecer 148.671 e respondeu às orientações oferecidas pelas Diretrizes e Normas Regulamentadoras de Pesquisa Envolvendo Seres Humanos (Resolução 466/2012 do Conselho Nacional de Saúde) e pela Resolução no 016/2000 do Conselho Federal de Psicologia. Estas Resoluções apontam que, na realização de uma pesquisa é imprescindível considerar alguns aspectos éticos em relação aos seus riscos e benefícios: autonomia, não maleficência, beneficência e justiça. Para atender tal exigência, esta pesquisa contou com o uso do Termo de Consentimento Livre e Esclarecido (TCLE) que oferece garantia aos direitos do participante. A pesquisa contou também com o Termo de Confidencialidade que garantiu ao participante o sigilo e confidencialidade das informações coletadas. Ambos os termos foram assinados em duas vias, ficando uma com o participante e outra via com o pesquisador responsável.

\section{Análise das Informações}

As informações foram analisadas coletivamente, de forma qualitativa. A análise de informações, na pesquisa qualitativa, tem como objetivo descobrir conceitos e relações das informações brutas. Busca organizar esses conceitos, de forma sistemática, em um esquema explanatório teórico (Strauss \& Corbin, 2008). Realizou-se também uma análise longitudinal dos casos, uma vez que se procurou identificar as semelhanças e particularidades entre os casos e a evolução na forma de pensar dos participantes em mais de um momento de coleta de dados (Anstey \& Hofer, 2004).

As entrevistas foram analisadas qualitativamente (Stake, 1994) e apresentadas em três eixos norteadores: (1) Práticas paternas de cuidado com o bebê; (2) Características do bebê e o comportamento do pai adolescente na realização das práticas de cuidados e (3) Responsabilidades assumidas entre os pais (mãe e pai). Estes eixos norteadores foram definidos a partir dos eixos investigados nas entrevistas que contemplavam os objetivos da pesquisa. A discussão das informações consiste em debater as categorias resultantes a partir de um diálogo com a literatura científica.

\section{RESULTADOS}

Os resultados são apresentados em forma de relato longitudinal. Em um primeiro momento apresentamse as informações oferecidas pelos adolescentes na entrevista realizada aos 40 dias após o nascimento do bebê e, posteriormente, as informações oferecidas na entrevista realizada no primeiro ano de vida da criança. Os nomes dos participantes e de familiares foram substituídos para manter o sigilo e confidencialidade de suas identidades.

CASO 01 - Rafael (20 anos), companheiro de Teresa (18 anos), pai de Camila. Tem ensino médio incompleto e é açougueiro. O casal mora com a família de Rafael desde o nascimento de Camila.

Período de até 40 dias após o Nascimento do Bebê: Os cuidados de Camila são realizados, principalmente, por Teresa. Rafael diz que ainda não se envolve muito, mas caso precisasse cuidar da filha teria que "ter uma aula antes com a Teresa". Ele relata que não sabe identificar a razão do choro de Camila, pois para ele, "tudo seria fome, eu já i faze umas dez mamadeiras". Rafael admite que "nessa hora quase nem pego porque não vou saber acalma mesmo... já deixo pra Teresa ou pra minha mãe". Ele ainda não deu banho na filha, pois diz que ela "tem pescocinho molinho e fico meio inseguro, porque ela chora bastante". Rafael diz que pretende se envolver mais com os cuidados de Camila quando ela estiver "mais firme, porque a gente vai pegando o jeito". Ele ajuda a Teresa em alguns cuidados quando está em casa. Ele admite que gosta de ficar com Camila quando "ela mostra que tá gostando do que faço pra ela". Rafael diz que, nos primeiros meses de vida de Camila, a responsabilidade de Teresa é com a alimentação da filha (amamentação) e sua responsabilidade é "não deixar faltar remédio, essas coisa". Entretanto, ele relata que pretende auxiliar nos cuidados de Camila e argumenta que pode fazer isso "ajudando a Teresa em outras coisas, ajuda a arruma a cama, lava a louça e também não irritando ela".

Um Ano após o Nascimento do Bebê: Rafael relata que, no momento, a responsabilidade pelos cuidados de Camila é a mesma entre ele e Teresa. A diferença é que a Teresa "cuida mais durante o dia, quando não tá trabalhando" e ele "cuida durante a noite", pois agora Teresa está estudando de noite. Rafael relata que agora "dá banho, dou comidinha pra ela e depois dou uma brincada antes dela dormir pra dar uma cansada né e depois fazer ela dormir". Ele diz que ocorreram mudanças nos cuidados de Camila, pois antes "eu era zero participações, eu só olhava, observava [...] agora eu tô bastante participativo". 
Quando questionado sobre uma responsabilidade exclusiva em relação aos cuidados da filha diz que "agora eu faço todas". Rafael admite que "no começo eu não participava muito né [...] mas a participação do pai é importante sempre [...] eu tenho ajudado mais de uns sete meses pra cá".

CASO 02 - Cássio (19 anos), pai de Samuel. Tem ensino médio incompleto e é militar. Cássio não coabitava com a companheira, Karina (16 anos), mas, no período de até 40 dias após o nascimento do bebê, o casal mantinha um relacionamento estável. Este relacionamento não se estendeu até o primeiro ano de vida de Samuel. No momento, Karina mora com Samuel na casa de sua família e Cássio mora na casa de seus pais. Samuel visita Cássio alguns dias na semana.

Período de até 40 dias após o Nascimento do Bebê: A principal responsável pelos cuidados de Samuel é "a Karina", e ele ajuda "dentro dos meus limites, da minha capacidade". Cássio relata que se sente inseguro para participar das práticas de cuidados do filho, por "medo de machuca e por falta de habilidade". Ele gostaria que Samuel fosse "mais ativo e espoleta, pois quero muito interagir com ele". Cássio trocou as fraldas ou a roupa de Samuel somente algumas vezes, mas já percebeu que "ele não gosta e chora bastante, chora bem forte, como se quisesse dizer para parar com aquilo". Ele descreve que o choro de Samuel o deixa "tenso", pois "não sei o que fazer para acalmar o choro dele". Cássio gosta, principalmente, de brincar e pegar Samuel no colo. Ele conta que quando "ele sorri ou faz caretas não dá vontade de sair de perto". Cássio relata que suas principais dificuldades são compreender o motivo do choro do bebê e "manusear com ele, pois é muito pequeninho". Para Cássio, as responsabilidades maternas se referem às práticas tais como a alimentação e a troca de fralda. As responsabilidades paternas são "banca eles dois, correr por eles o que for necessário".

Um Ano após o Nascimento do Bebê: Cássio e Karina se separaram nos primeiros meses de vida de Samuel. Por esta razão, quando o bebê está na casa de Cássio, recebe seus cuidados aos finais de semana e alguns dias da semana. Ele relata que a principal responsável pelos cuidados de Samuel em sua casa "é a minha mãe, por eu não pode tá sempre com ele né, mas meu pai e minha irmã me ajudam também". Quanto a sua participação nos cuidados do filho, Cássio descreve que "antes não me envolvia muito sabe? Diferente de agora que eu já, por minha conta, quero tá sempre presente, quando ele tá fazendo as coisa. [...] Quando eu tô com ele, até a mãe me diz que sou chato, to toda hora cuidando a fralda, oferecendo comida [...]. Cássio diz que "esse tipo de coisa eu não fazia antes quando ele era mais pequeninho [...] agora eu gosto de dá banho, de escolher a roupa dele, dar comida pra ele". Entretanto, ele ressalta que não tem nenhuma responsabilidade que seja exclusivamente sua, pois "eu não to sempre com ele, então tudo que eu faço, o pessoal aqui de casa faz também". Ao ser questionado sobre quais as responsabilidades são do pai ou da mãe neste momento, Cássio diz que "as responsabilidades são as mesmas, eu cuido dele quando tá comigo e ela [Karina] quando tá com ele".

CASO 03 - Jonas (20 anos), companheiro de Mariana (16 anos), pai de Guilherme. Tem ensino fundamental incompleto e é eletricista. O casal morou com a família de Mariana nos primeiros meses de vida do bebê. No momento, o casal e Guilherme moram sozinhos em outra casa.

Período de até 40 Dias após o Nascimento do Bebê: Os cuidados de Guilherme ficam, principalmente, sob a responsabilidade de Mariana. Jonas ajuda quando está em casa, pois trabalha o dia todo. Mas diz que "cuido, dou banho, troca a fralda dele". Relata que, às vezes, prefere cuidar de Guilherme, pois têm experiência em cuidar crianças menores, como do irmão e do bebê recém-nascido de uma ex-namorada. A mãe de Mariana ajuda também, "limpando a casa, às vezes". Jonas diz que o filho é "tranquilo" e chora somente quando está com fome, sono ou alguma "dorzinha". Nestes momentos, ele conta que busca acalmar o filho de diferentes maneiras. Jonas conta detalhes do processo de amamentação do filho, como intervalos de mamadas e diz que "quando é na mamadeira sou eu quem dá". Seu interesse pelo bebê é decorrente do desejo de (re) significar a relação de desamor que teve com o próprio pai: "preciso saber como ele ta, como se comporta, quero ficar perto dele e ele gostar de mim, não quero que seja como foi com meu pai". Ele enfatiza que gosta de "brincar com ele, cuidar ele dormindo, olhar a perfeição do rostinho, das mãozinhas". Para Jonas, as principais responsabilidades maternas se referem à "alimentação e sabe identifica o que ele tem" e as paternas são em relação à "não deixar falta nada pra dentro de casa". Entretanto, "os cuidados do Guilherme é de responsabilidade dos dois e quando eu to em casa, eu divido tudo pela metade com ela".

Um Ano após o Nascimento do Bebê: A principal responsável pelos cuidados de Guilherme continua sendo "a mãe dele que fica mais tempo com ele". No entanto, Jonas ainda faz questão de ajudar Mariana nos cuidados com o filho. Ele ressalta que não tem uma responsabilidade exclusiva, mas que "ajudo em 
todos os cuidados, todos os que a mãe dele também faz [...] todos eu continuo fazendo desde que ele era pequeno". Eles não moram mais com a mãe de Mariana, por isso quem está cuidando do bebê "é só nós mesmo", diz Jonas. Ele ressalta não enxergar diferenças na rotina de cuidados, entretanto destaca que "a preocupação da gente é igual a de antes [...] mas os cuidados aumentam a cada dia que passa, então a gente tem que tá sempre atento e tentando se comunica com ele". Jonas destaca sua preocupação com a alimentação do filho: "é uma briga pra come". Em relação a amamentação, ele destaca que "a gente dá mama, tá tentando tira o peito dele [...] tamo tentando troca pelo leite na mamadeira, que tá bem complicado. [...] Tá dificil dele pega a comida de sal, então a gente botou a papinha pronta". Esta transição alimentar está sendo realizada, pois Mariana "está tentando fazer um curso e fica bem complicado com ele mamando no peito ainda". Para Jonas, as responsabilidades maternas com o passar do tempo continuam as mesmas: "é tá cuidando dele, dando alimentação durante o dia que eu não to em casa". Sobre as responsabilidades paternas, ele diz que "é igual as da mãe". Jonas ressalta que "faço questão de participar, pra ele senti minha presença como pai, papel do pai é bem importante [...] tem que estar presente o tempo todo".

\section{DISCUSSÃO}

A discussão dos resultados foi realizada a partir da comparação dos dados obtidos nas entrevistas com estudos científicos existentes sobre a temática da paternidade.

\section{Práticas Paternas de Cuidado com o Bebê}

Esta categoria apresenta os aspectos sobre o engajamento do pai adolescente nas práticas de cuidados diretos com o bebê. Entende-se por cuidados diretos aquelas tarefas que são desenvolvidas para suprir algumas das necessidades da criança, como as que são relacionadas a alimentação, banho, troca de fraldas e roupas, sono e brincadeiras.

\section{Semelhanças}

As práticas de cuidados desenvolvidas pelos pais adolescentes foram influenciadas por outras pessoas, como a companheira ou membros das famílias de origem, principalmente a avó materna e paterna do bebê. No período de até 40 dias após o nascimento, todos os pais dividiram, de certa forma, os cuidados da criança com a companheira. Nos casos relatados, as companheiras permitiram a participação dos pais em todas as tarefas de cuidados. Isso pode ser fruto de uma boa relação entre pai e mãe adolescentes, uma vez que esse tipo de relação permite a construção de relacionamentos saudáveis e de uma parentalidade mais eficaz para a criação e educação da criança (Scholl, 2012). Percebe-se que a mãe pode exercer uma função catalisadora do papel paterno, ao permitir e incentivar a aproximação entre pai e bebê (Herzog, Umanã-Taylor, Madden-Derdich, \& Leonard, 2007; Scholl, 2012).

No período de até 40 dias após o nascimento do bebê, Rafael (caso 01) e Cássio (caso 02) desempenharam timidamente os cuidados com seus filhos. Tal fato pode ocorrer devido ao processo de maior aproximação entre mãe e bebê que ocorre nos primeiros dias após o nascimento. Observa-se que a mulher desempenha, nesse momento, a função de principal cuidadora e o homem estabelece uma relação de suporte, seja financeiro e/ou emocional, a díade mãe-bebê (Jager \& Bottoli, 2011; Monteiro, Veríssimo, Santos, \& Vaughn, 2008; Pimenta, Veríssimo, Monteiro, \& Costa, 2010). Além disso, no contexto da paternidade adolescente, esse distanciamento inicial do pai pode ser decorrente de sentimentos de insegurança, em face da necessidade de ter que assumir, precocemente, responsabilidades sobre as escolhas de vida afetivas e laborais (Gordon, Watkins, Walling, Wilhelm, \& Rayford, 2011).

Ainda, destaca-se que o engajamento dos três pais adolescentes com seus filhos pode ser pensado a respeito da classe social em que vivem. A dificuldade inicial dos pais tomarem contato com a realidade corporal dos filhos e as práticas de cuidados pode ter relação com o que se espera socialmente deles como homens. Em classes populares os homens são valorizados principalmente enquanto provedores econômicos e de respeito e tendem a excluir contatos e cuidados corporais, embora se espere que o pai tenha proximidade emocional com o filho. Tais expectativas seriam construídas tanto na família quanto através de diversos contatos sociais (Bustamante, 2005).

As práticas de cuidados e o comprometimento dos pais adolescentes modificaram-se ao longo do primeiro ano de vida da criança. Fica evidente, a partir dos relatos dos pais entrevistados que o engajamento paterno é progressivo, ou seja, aumenta conforme o crescimento do bebê (Jager \& Bottoli, 2011; Pimenta et al., 2010). Visualiza-se isso nos casos 01 e 02, com a exceção de Jonas (caso 03), que já tinha experiência em relação aos cuidados de um recém-nascido e, por isso, demonstrou maior participação desde os momentos iniciais.

No primeiro ano de vida da criança, constatase a construção do novo papel paterno por parte 
dos três pais, sendo desenvolvidos sentimentos de maior autonomia e segurança para atender às necessidades do bebê ao longo do tempo, o que foi vivenciado através da divisão das tarefas de cuidados. O desenvolvimento/maturação física da criança aproxima os pais de seus filhos, pois esses as enxergam como menos frágeis e mais ativas. Isso permite o estabelecimento de uma relação de confiança e, consequentemente, a diminuição da ênfase no papel da mãe e da crença de que a mesma é mais capacitada para exercer a função do cuidado (Jager \& Bottoli, 2011; Monteiro et al., 2008; Pimenta et al., 2010).

No caso 01, Rafael passa há despender mais tempo para ajudar a companheira a cuidar da filha no primeiro ano de vida. Ele fica responsável por desempenhar as tarefas de cuidados (trocar fralda, dar banho, fazer dormir e alimentação) enquanto Teresa está estudando a noite. No caso 03, Jonas já participava ativamente dos cuidados do filho, desde seus primeiros dias, em função de ter experiência prévia. Ele relata que durante o primeiro ano da criança desempenhou todas as tarefas de cuidados e ajudava a companheira sempre que necessário. Portanto, Jonas não percebe mudanças na sua rotina desde o nascimento até o primeiro ano, pois considera que ambos cuidam do filho ativamente.

Por outro lado, destaca-se que o vínculo estabelecido entre os pais e a criança depende de características do pai, da mãe, do bebê e do contexto no qual a família está inserida. Quando a mãe trabalha ou estuda, existe uma tendência maior para a promoção da participação paterna (Pimenta et al., 2010). Isso foi possível de ser verificado nos casos de Rafael e Jonas. O primeiro cuida do filho durante a noite para a companheira estudar e o segundo auxilia na transição da alimentação da criança, do peito para a mamadeira, para que a mãe possa fazer um curso. No entanto, parece que Jonas apresenta um maior engajamento em seu novo papel (pai/cuidador) ao auxiliar em todos os cuidados da criança.

O engajamento paterno pressupõe viver uma experiência, fundada em práticas. Jonas, apesar de ser pai pela primeira vez, já exerceu esses cuidados em relação ao irmão e ao bebê da ex-namorada. Os demais pais, Rafael e Cássio, parecem estar construindo sua experiência de cuidado e percepção sobre a paternidade. Ao compararmos seus relatos no período de até 40 dias e no primeiro ano da criança, percebe-se um maior amadurecimento e uma postura mais participativa e autoconfiante ao longo do desenvolvimento do filho, pois o comprometimento com esse novo papel requer uma série de adaptações. Através das falas dos pais pode-se supor que os três conseguiram se adaptar a esse novo papel e se envolveram efetivamente com os filhos (Cruz, 2011; Jager \& Bottoli, 2011; Piccinini, Silva, Gonçalves, Lopes, \& Tudge, 2012).

\section{Particularidades}

Pode-se inferir que devido à separação do casal, Cássio (caso 02) começa a se envolver mais nos cuidados do filho ao longo de seu primeiro ano de vida. Diferente da situação de Rafael (caso 01) e de Jonas (caso 03), que permanecem em um relacionamento com suas companheiras. Assim, quando Cássio está em casa divide as tarefas de cuidados do ilho com sua família (mãe, pai e irmã) e, principalmente, com a própria mãe (avó paterna).

A separação conjugal pode ser percebida como um fator de risco no comprometimento paterno na vida da criança (Cruz, 2011), uma vez que a ausência do pai ainda é mais frequente que a da mãe e isso pode favorecer a total distância dos filhos (Bottoli, 2010). Entretanto, neste caso, apesar de não coabitar com o filho, o fato não parece ter influenciado de maneira negativa o engajamento com Samuel. Isso pode ser explicado por fatores de proteção demonstrados por Cássio, tais como: ter uma rede apoio, ter mãe e pai presentes, e ter um emprego. Desse modo, não morar junto com o filho não significa que o pai esteja ausente emocional e/ou psicologicamente. Ao contrário, nas últimas duas décadas presencia-se um número ascendente de pais separados que buscam a aproximação dos filhos (Cruz, 2011; Fagan, Palkovitz, Roy, \& Farrie, 2009).

Outra particularidade é observada no caso de Jonas (03), que demonstra claramente o quanto a questão do "modelo de pai" influencia na relação entre paibebê desenvolvido por ele com o filho quando afirma que não quer ser como o seu pai. Apesar da família de origem do pai adolescente servir de modelo direto ou indireto, este padrão pode ser repetido ou evitado. Jonas rechaça o modelo de paternidade de sua família de origem para construir seu próprio padrão, a fim de evitar falhas cometidas pelo seu pai (Levandowski, Piccinini, \& Lopes, 2009; Scholl, 2012).

$\mathrm{O}$ adolescente busca referências do significado de ser pai no próprio modelo de pai que possuiu na sua criação. Porém, muitas vezes, esses jovens possuem uma falta de modelos positivos ou simplesmente essas referências não existem. Em contrapartida, pais adolescentes que foram criados em um ambiente que se primava por uma relação positiva, saudável e possuíam um pai presente tendem a imitar esse modelo no desempenho de seu papel (Deus, Jager, Souto, \& Dias, 2013; Gabriel \& Dias, 2011; Scholl, 2012). Com 
isso, empenham-se nos cuidados e no cotidiano dos filhos de modo a construir um modelo de paternidade mais participativa.

\section{Características do Bebê e o Comportamento do Pai Adolescente na Realização de Práticas de Cuidados}

Esta categoria discute sobre como as características do bebê, de ordem comportamental, física e psicológica, podem influenciar o comportamento do pai diante das práticas de cuidados diretos, no seu engajamento e nas manifestações de afeto e carinho com os filhos. Ressalta-se ainda sobre como esse processo acontece de maneira bidirecional, ou seja, que o comportamento do bebê também pode ser influenciado pelas características e atitudes paternas.

\section{Semelhanças}

Durante o período de até 40 dias após o nascimento do bebê, Rafael (caso 01) e Cássio (caso 02) ressaltam que se envolveram timidamente nos cuidados dos filhos. Entretanto, ao longo do primeiro ano de vida passam a participar mais ativamente. $\mathrm{O}$ que difere do caso 03 (Jonas), que sempre participou integralmente das tarefas de cuidados. Muitos pais podem ter dificuldades em criar um vínculo sólido e concreto com o bebê por ainda não visualizá-lo e senti-lo, o que passa a ser construído de forma lenta e gradual após o nascimento e ao longo de seu desenvolvimento (Manfroi, Macarini, \& Vieira, 2011).

As diferenças entre as atitudes dos adolescentes podem ser explicadas devido à presença de características físicas do bebê, como a fragilidade, que acabam deixando os pais inseguros para realizar os cuidados. Isto é evidenciado nas falas de Rafael (caso 01) e Cássio (caso 02), uma vez que descrevem seus respectivos filhos como "molinho" ou "muito frágil" e isso faz com que elejam as companheiras como mais habilidosas e delicadas para realizar as tarefas de cuidados (Piccinini et al., 2012).

Igualmente, as características comportamentais do bebê podem estimular ou desestimular as práticas de cuidados paternas. Rafael (caso 01) e Cássio (caso 02), no período de até 40 dias após o nascimento, mencionam a respeito do choro das crianças e afirmam que este gera tensão e ansiedade por não saberem o que fazer. Sentimentos, como inabilidade, insegurança e ansiedade dos pais diante dos desafios intrínsecos ao seu papel, podem dificultar seu engajamento com os cuidados da criança (Bronfenbrenner, 2011; Levandowski \& Piccinini, 2002; Piccinini et al., 2012). Nesses casos o choro dos bebês pode ter levado os pais a se afastarem das tarefas.
As características e a capacidade dos bebês em interagir com aqueles que lhe cuidam também é um aspecto de grande importância para o desenvolvimento da responsividade, do apego seguro e de um bom vínculo entre a criança e as figuras parentais (Manfroi, Macarini, \& Vieira, 2011). Os relatos dos pais ressaltam a importância da responsividade da criança aos estímulos paternos. Rafael (caso 01) relata que Camila demonstra que gosta do que ele faz para ela, já Cássio (caso 02) afirma que não tem vontade de sair de perto de Samuel com as caretas que ele faz. Jonas (caso 03), por sua vez, descreve Guilherme como uma criança calma que chora apenas quando está com fome, sono ou dor.

Portanto, esta responsividade do bebê é imprescindível para que se dê essa relação, que é bidirecional, ou seja, não somente os pais influenciam o comportamento da criança, como estas também influenciam o dos pais, que se adéquam às novas demandas dos filhos (Bronfenbrenner, 2011; Monteiro et al., 2008). Por exemplo, a utilização de brincadeiras e gestos de carinho, como explicitado por Cássio (caso 02), possibilita a criação de um bom vínculo afetivo entre pai e bebê (Farias, 2008). Além disso, fazem com os pais se sintam mais acolhedores, ternos e capazes de estabelecer vínculos significativos e profundos com o filho (Sutter \& Bucher-Maluschke, 2008).

Pode-se concluir que as características psicológicas da criança também interferem na relação paibebê. Uma criança que responde mais aos estímulos acaba interagindo mais e retroalimentando a relação. $\mathrm{O}$ que gera sentimentos positivos, de confiança e efetividade nos pais que se emocionam ao constarem as reações dos bebês em relação às tarefas que desempenham. Em razão disso, os pais atestam que a sua presença é importante para o filho e se motivam pela busca gradativa do retorno afetivo (Farias, 2008).

Por outro lado, a baixa responsividade e a dificuldade de comunicação tornam-se um problema ainda maior quando se trata de pais adolescentes, pois esses podem ter pouca experiência. Além disso, podem apresentar expectativas fantasiosas e certo desconhecimento sobre o desenvolvimento infantil (Levandowski \& Piccinini, 2002). Porém, quando existe interesse dos pais em se envolver com os filhos, pode haver a aquisição de práticas de cuidados positivas que os auxiliarão a considerar seus filhos como uma prioridade em suas vidas (Scholl, 2012). Com isso, os pais podem dedicar-se mais a criança, de modo a manter um bom vínculo, relacionamento saudável e assumir as responsabilidades relacio- 
nadas à paternidade. No discurso dos adolescentes não foram detectadas particularidades sobre as características do bebê e o comportamento do pai adolescente na realização de práticas de cuidados.

\section{Responsabilidades Assumidas entre os Pais (mãe e pai)}

Esta categoria discute como os pais adolescentes percebem as responsabilidades maternas e paternas assumidas com os filhos. Essas estão diretamente relacionadas com os cuidados diretos (alimentação, banho, sono, troca de fralda e de roupas) e indiretos (sustento financeiro) prestados a criança e ligadas aos papéis de gênero.

\section{Semelhanças}

No período de até 40 dias do bebê, os adolescentes descrevem responsabilidades relacionadas ao sustento familiar: "não deixar faltar remédio", "banca eles dois", e "não deixar faltar nada pra dentro de casa". Os cuidados diretos ao bebê, como troca de fralda, alimentação e banho foram identificados como responsabilidades maternas. Percepções como estas são comuns em pais adolescentes (Silveira et al., 2013). Cabe lembrar que as responsabilidades parentais estão fortemente ligadas aos papéis de gênero. Apesar das transformações dos modelos familiares, o papel da mulher ainda está relacionado ao cuidado e o do homem permanece associado ao de provedor (Jager \& Bottoli, 2011; Pimenta et al., 2010; Vieira \& Nascimento, 2014).

No entanto, a definição estática de responsabilidades parentais, parece se diluir gradativamente ante as outras demandas e responsabilidades que esses pais assumem em relação aos cuidados dos filhos, tais como o reconhecimento da importância de sua presença e/ou participação (relatada pelos três pais) e a prestação de auxílio a companheira para que esta possa cuidar de outros interesses (caso 01 e 03). Ao serem questionados novamente sobre as responsabilidades maternas e paternas, durante esse período, todos os pais ressaltam que ambos têm os mesmos encargos. Como ter que trabalhar ou estudar, dar banho, brincar e alimentar a filha (caso 01). Ou ainda com a troca de fraldas e a alimentação do filho (caso 02).

Por muito tempo, os pais foram afastados socialmente das relações de cuidados. Atualmente, há uma geração de homens mais interessados em auxiliar as companheiras nas atividades domésticas diárias, na maior participação nos cuidados e em manter uma relação de proximidade com os filhos
(Lamy, 2012). Isso parece ocorrer pela influência do novo modelo de pai, que preza pela afetividade, cuidado e proximidade familiar. Trata-se da chamada nova paternidade, onde existe maior participação masculina nas tarefas domésticas e cuidados com os filhos e uma mudança de atitudes parentais. Os pais passam a se apropriar do novo papel, em especial quando a criança passa a ter mais autonomia e apresentar maior responsividade aos seus estímulos (Cruz, 2011; Levandowski \& Piccinini, 2006; Monteiro et al., 2008; Silveira et al., 2013).

As pressões e as expectativas sociais são fatores que influenciam igualmente na distribuição das responsabilidades. Isso porque ainda é esperado que o homem sustente a família e se insira no mundo do trabalho e a mulher cuide da família. Verifica-se esse fato na situação vivenciada pelos pais adolescentes deste estudo, uma vez que os três trabalham para sustentar os filhos e suas companheiras são donas de casa (Monteiro et al., 2008; Pimenta et al., 2010).

Ainda existe certa confusão em relação aos papéis parentais. $\mathrm{O}$ desempenho das responsabilidades maternas e paternas ainda repercute nas famílias atuais. Porém, também existem aspectos diferentes e em constante mutação. A única certeza que se tem é que o modelo parental e divisão de tarefas baseado nos gêneros não define totalmente a demanda das novas famílias. As mães buscam adentrar no mundo do trabalho, enquanto os pais buscam maior proximidade dos filhos. Neste momento, as famílias encontram-se em uma fase de reconstrução de papéis (Levandowski \& Piccinini, 2006; Monteiro et al., 2008; Pimenta et al., 2010).

As responsabilidades assumidas entre o pai e a companheira também podem ser influenciadas pelo tipo de união estabelecida pelo casal, visto que, muitas vezes, esses jovens não são casados. Isso pode alterar o nível de responsabilidade paterna e distribuição das atividades relacionadas com o bebê (Herzog et al., 2007; Scholl, 2012). Nos casos 01 e 03, pode-se notar que as características da relação do casal não alteraram o nível de responsabilidade dos pais (união estável). Porém, no caso 02, em que houve a separação conjugal, pode ter ocorrido influencia, pois Cássio envolveu-se e aproximou-se mais do filho e passou a ajudar nos cuidados com o bebê. Talvez isso não tivesse acontecido se o casal permanecesse em uma união estável ao longo do primeiro ano do filho.

Portanto, o papel do pai, assim como o da mãe é de grande importância para o desenvolvimento da criança. Isso porque cada um possui as suas especificidades, o que faz com que funcionem em polos 
diferentes. $\mathrm{O}$ pai tem uma função complementar à da mãe, no sentido de prover as necessidades básicas da criança (materialmente), e também, pelas descobertas que realiza em relação às capacidades do bebê. Estas contribuem para a construção de sua identidade paterna e confiança no desempenho de seu papel (Paquette, 2004). No discurso dos adolescentes não foram detectadas particularidades sobre as responsabilidades assumidas entre os pais (mãe e pai).

\section{CONSIDERAÇÕES FINAIS}

O objetivo principal deste estudo foi verificar as mudanças ocorridas em relação ao envolvimento do pai adolescente nas práticas de cuidados ao longo do primeiro ano de vida. Através da análise longitudinal dos relatos foi possível concluir que os pais adolescentes conseguiram se engajar satisfatoriamente com seus filhos ao longo do primeiro ano de vida da criança. As práticas de cuidados paternas foram influenciadas e estimuladas por fatores como a necessidade de trabalhar ou estudar das companheiras, a separação conjugal e a convivência com a família de origem. Estes fatores contribuíram para um maior comprometimento do pai com os filhos e no desenvolvimento de maiores habilidades para as tarefas de cuidados.

As características físicas, comportamentais e psicológicas do bebê também contribuíram para que os pais adolescentes participassem mais (ou menos) das práticas de cuidados. Assim como as características e a personalidade de cada pai diante das reações da criança. Outro aspecto presente nos relatos dos pais é a divisão de papéis vivida e as responsabilidades consideradas maternas e paternas. Os adolescentes ressaltam que a companheira é a principal cuidadora do bebê. Isso pode ser justificado por influências culturais e sociais que ainda estão muito presentes na sociedade contemporânea. Porém, os adolescentes entrevistados pareceram se mostrar engajados na realização de atividades com seus filhos.

A partir dos resultados encontrados, salientase a importância dos serviços de saúde e outras instituições que trabalham com o público do estudo reconhecerem a capacidade do adolescente em assumir as responsabilidades frente a paternidade e facilitarem o desempenho de seu papel paterno. Os profissionais de saúde podem potencializar o envolvimento do pai, tanto o adolescente como o adulto, em participar das práticas de cuidados e acompanhar a gestação desde o pré-natal. Entendese que o mesmo apoio oferecido as mulheres diante da maternidade, deve ser estendido aos pais frente a paternidade, em todos os contextos e idades. Destacase o benefício do estudo longitudinal utilizado como delineamento neste estudo. Isso possibilitou visualizar o desenvolvimento dos pais ao longo deste primeiro ano de vida da criança diante das tarefas de cuidados. Nota-se que as experiências vividas durante esse período influenciaram positivamente a maneira como os adolescentes do estudo perceberam a paternidade.

Como limitações do estudo destacam-se o número reduzido de participantes, uma vez que isso não permite que seus resultados possam ser generalizados para outros grupos de pais adolescentes. Entretanto, é importante destacar a dificuldade encontrada para a realização de entrevistas com pais homens em geral. Este público não está acostumado ainda a participar de estudos sobre investigação parental. Isso está relacionado também a aspectos culturais e sociais. Ainda, sobre a quantidade de participantes, salienta-se que embora o estudo de caso coletivo permita incluir um número maior de casos, optou-se por analisar somente as respostas dos participantes com informações mais completas e ricas em significados. Entretanto, isso não significa que os outros pais, inclusive os que foram desistindo ao longo da pesquisa, não se envolviam com seus bebês. Mas que eles não conseguiram expressar verbalmente, de forma clara, como ocorria esse envolvimento, o que limitou a análise dessas informações. Outra limitação do estudo diz respeito ao registro das informações sobre a situação da entrevista, uma vez que, caso fossem acrescentadas teríamos maior riqueza de detalhes quanto as reações dos participantes.

Sugerem-se realizar novos estudos que investiguem a participação paterna em práticas de cuidados que explorem outras características que não se fazem presentes neste estudo. Como, pais que não possuem uma relação amorosa com a companheira, que sejam de outras classes econômicas, ou ainda, adolescentes que se tornam pais mais jovens (antes dos 18 anos). Outro aspecto que merece atenção seria a investigação de pais adolescentes que tem filhos com companheiras adultas. Considera-se também explorar outros tipos de delineamento para pesquisas com pais adolescentes, como a observação constante, por um determinado período de tempo, das práticas de cuidados durante os primeiros anos de vida da criança (0 a 3 anos). Portanto, estudos que envolvam pais adolescentes devem ser ainda mais explorados, pois a temática é relevante e precisa de novas intervenções para dar conta dos novos vínculos construídos nessas famílias. 


\section{REFERÊNCIAS}

Anstey, K. J. \& Hofer, S. M. (2004). Longitudinal designs, methods and analysis in psychiatric research. Australian in New Zealand Journal of Psychiatry, 38(3), 93-104. Recuperado de $<$ http://anp.sagepub.com/content/38/3/93>. http:// dx.doi.org/10.1080/j.1440-1614.2004.01343.x

Bottoli, C. (2010). Paternidade e separação conjugal: a perspectiva do pai. (Dissertação de Mestrado). Universidade Federal de Santa Maria, Santa Maria, RS.

Brazelton, T. B. \& Cramer, G. (2002). As primeiras relações (2ª ed.). São Paulo: Martins Fontes.

Bronfenbrenner, U. (2011). Bioecologia do desenvolvimento humano: tornando os seres humanos mais humanos. Tradução André de Carvalho-Barreto. Porto Alegre: Artmed.

Bustamante, V. (2005). Ser pai no subúrbio ferroviário de Salvador: um estudo de caso com homens de camadas populares. Psicologia em Estudo, 10(3), 393-402. http://dx.doi.org/10.1590/S1413-73722005000300007

Carvalho, G. M., Merighi, M. A. B., \& Jesus, M. C. P. (2009). Recorrência da parentalidade na adolescência na perspectiva dos sujeitos envolvidos. Texto \& Contexto-Enfermagem (Florianópolis), 18(1), 17-24. Recuperado de <http://www.scielo.br/scielo.php?script=sci_arttext\&pid=S0104-07072009000100002\&lng=en\&tlng=pt $>$. http://dx.doi.org/10.1590/S0104-07072009000100002.

Conselho Federal de Psicologia. (2000). Resolução CFP ño 016. Dispõe sobre a realização de pesquisa em Psicologia com seres humanos. Brasília. Recuperado de $<$ http://www.fiocruz.br/ipec_novo/media/11PesquisaPsicologiaSeresH umanos.pdf>.

Conselho Nacional de Saúde. (2012). Resolução no 466. Dispõem sobre diretrizes e normas regulamentadoras de pesquisas envolvendo seres humanos. Brasília. Recuperado de <http://conselho.saude.gov.br/resolucoes/2012/Reso466.pdf>.

Cruz, M. F. P. (2011). Envolvimento do pai no desenvolvimento da criança em idade escolar em casais divorciados/ separados. (Dissertação de Mestrado). Faculdade de Psicologia e de Ciências da Educação da Universidade do Porto, Portugal.

Deus, M. D. Jager, M. E., Souto, D. C., \& Dias, A. C. G. (2013). Modelos de paternidade disponíveis para pais adolescentes. Anais $28^{a}$ Jornada Acadêmica Integrada. Universidade Federal de Santa Maria, Santa Maria, RS.

Goetz, E. R. \& Vieira, M. L. (2011). Pai real, pai ideal: o papel paterno no desenvolvimento infantil. Curitiba: Juruá.

Fagan, J., Palkovitz, R., Roy, K., \& Farrie, D. (2009). Pathways to paternal engagement: longitudinal effects of risk and resilience on nonresident fathers. Developmental Psychology, 45(5), 1389-1405. http://dx.doi.org/10.1037/a0015210

Farias, G. C. (2008). O que os bebês sabem? Um modo diferenciado de pensá-los. Pensar a prática, 11(2), 115-124. http://dx.doi.org/10.5216/rpp.v11i2.2396

Gabriel, M. R. \& Dias, A. C. G. (2011). Percepções sobre a paternidade: descrevendo a si mesmo e o próprio pai como pai. Estudos de Psicologia, 16(3), 253-261. Recuperado de <http:/www.scielo.br/scielo.php?script=sci_arttext\&pid $=$ S1413294X2011000300007\&lng=pt\&tlng=pt>. http://dx.doi.org/10.1590/S1413-294X2011000300007

Gordon, D. M., Watkins, N. D., Walling, S. M., Wilhelm, S., \& Rayford, B. S. (2011). Adolescent fathers involved with child protection: social workers speak. Child Welfare, 90(5), 95-114.

Herzog, M. J., Umanã-Taylor, A., Madden-Derdich, D. A., \& Leonard, S. A. (2007). Adolescent mothers' perceptions of fathers' parental involvement: satisfaction and desire for involvement. Family Relations, 56, 244-257. Recuperado de <http://onlinelibrary.wiley.com/doi/10.1111/j.1741-3729.2007.00456.x/pdf >. http://dx.doi.org/10.1111/j.17413729.2007.00456.x

Jager, M. E. (2014). O envolvimento paterno de adolescentes com o bebê. (Dissertação de Mestrado). Universidade Federal de Santa Maria, Santa Maria, RS.

Jager, M. E. \& Bottoli, C. (2011). Paternidade: vivência do primeiro filho e mudanças familiares. Psicologia: Teoria e Prática, São Paulo, 13(1), 141-153. Recuperado de <http://pepsic.bvsalud.org/scielo.php?script=sci arttext\&pid=S1516-36872011000100011\&lng=pt\&tlng=pt>.

Jager, M. E. \& Dias, A. C. G. (2012). Paternidade adolescente e a relação pai-bebê no primeiro ano de vida da criança. Projeto de Pesquisa. Programa de Pós-Graduação em Psicologia. Universidade Federal de Santa Maria, Santa Maria, RS.

Lamb, M. E., Pleck, J. H., Charnov, E. L., \& Levine, J. A. (1987). A biosocial perspective on paternal behavior and involvement. In J. B. Lancaster, J. Altaman, A. Rossi, \& R. L. Sherrod (Eds.). Parenting across the lifespan: Biosocial perspectives (pp. 11-42). New York: Academic.

Lamy, Z. C. (2012). Reflexões sobre o apoio paterno: profissionais e serviços de saúde contribuem para seu desenvolvimento? Revista Paulista de Pediatria, 30(3), 304-305. Recuperado de <http://www.scielo.br/scielo. php?script=sci arttext\&pid=S0103-05822012000300001\&lng=en\&tlng=pt>. http://dx.doi.org/10.1590/S010305822012000300001

Levandowski, D. C. \& Piccinini, C. A. (2002). A interação pai-bebê entre pais adolescentes e adultos. Psicologia Reflexão e Crítica, 15(2), 413-424. Recuperado de <http:/www.scielo.br/scielo.php?script=sci_arttext\&pid=S010279722002000200018\&lng=en\&tlng=pt>. http://dx.doi.org/10.1590/S0102-7972200200020001̄

Levandowski, D. C. \& Piccinini, C. A. (2006). Expectativas e sentimentos em relação à paternidade entre adolescentes e adultos. Psicologia: Teoria e Pesquisa, 22(1), 17-28. Recuperado de <http://www.scielo.br/scielo.php? script=sci arttext\&pid=S0102-37722006000100003\&lng=en\&tlng=pt>. http://dx.doi.org/10.1590/S0102-37722006000100003 
Levandowski, D. C., Piccinini, C. A., \& Lopes, R. C. S. (2009). O processo de separação-individuação em adolescentes do sexo masculino na transição para a paternidade. Psicologia: Reflexão e Crítica, 22(3), 353-361. Recuperado de <http://www.scielo.br/scielo.php?script=sci_arttext\&pid=S0102-79722009000300005\&lng=en\&tlng=pt $>$. http://dx.doi.org/10.1590/S0102-79722009000300005

Manfroi, E. C., Macarini, S. M., \& Vieira, M. L. (2011). Comportamento parental e o papel do pai no desenvolvimento infantil. Revista Brasileira de Crescimento e Desenvolvimento Humano, 21(1), 59-69. Recuperado de <http://pepsic. bvsalud.org/scielo.php?script=sci_arttext\&pid=S0104-12822011000100007\&lng=pt\&tlng=pt>.

Meincke, S. M. K. \& Carraro T. E. (2009). Vivência da paternidade na adolescência: sentimentos expressos pela família do pai adolescente. Texto Contexto Enfermagem, 18(1), 83-91. http://dx.doi.org/10.1590/S0104-07072009000100010

Monteiro, L., Verissimo, M., Santos, A. J., \& Vaughn, B. E. (2008). Envolvimento paterno e organização dos comportamentos de base segura das crianças em famílias portuguesas. Análise Psicológica, 26(3), 395-409. Recuperado em <http:// www.scielo.gpeari.mctes.pt/scielo.php? script=sci_arttext\&pid=S0870-82312008000300003\&lng=pt\&nrm=iso $>$.

Neri, M. C. (Coord). (2010). A nova classe média, o lado brilhante dos pobres. Rio de Janeiro: FVG, CPS.

Nogueira, M. J., Martins, A. M., Schall, V. T., \& Modena, C. M. (2011). "Depois que você vira um pai..." : adolescentes diante da paternidade. Adolescência \& Saúde, 8(1), 28-34. Recuperado em 28 out. 2014, de <http://www. adolescenciaesaude.com/detalhe_artigo.asp?id=262>.

Paquette, D. (2004). Theorizing the father-child relationship: mechanisms and developmental outcomes. Human Development, 47(4), 193-219. http://dx.doi.org/10.1159/000078723

Piccinini, C. A., Silva, M. R., Gonçalves, T. R., Lopes, R. C. S., \& Tugde, J. (2012). Envolvimento paterno aos três meses de vida do bebê. Psicologia: Teoria e Pesquisa, 28(3), 303-314. http://dx.doi.org/10.1590/S0102-37722012000300006

Pimenta, M., Veríssimo, M., Monteiro, L., \& Costa, I. P. (2010). O envolvimento paterno de crianças a frequentar o jardim-de-infância. Análise Psicológica, Lisboa, Portugal, 28(4), 565-580. Recuperado de <http://www.scielo.gpeari. mctes.pt/scielo.php?script=sci_arttext\&pid=S0870-82312010000400002\&lng=pt\&nrm=iso>.

Sampaio, K. J. A. J., Villela, W. V., \& Oliveira, E. M. (2014). Significados atribuídos a paternidade por adolescentes. Acta Paulista de Enfermagem, 27(1), 01-05. http://dx.doi.org/10.1590/1982-0194201400002

Scholl, M. F. (2012). What about the dads: a case study of young fathers of babies born to adolescent mothers. (Tese of Philosophy Education). George Mason University, Fairfax, VA.

Souto, D. C., Jager, M. E., \& Dias, A. C. G. (2013). A construção histórica da paternidade. Anais $28^{a}$ Jornada Acadêmica Integrada. Universidade Federal de Santa Maria, Santa Maria, RS.

Silveira, T. C., Jager, M. E., Souto, D. C., Costa, E. F. L., Coradini, F. R., \& Dias, A. C. G. (2013). Diferenças nas responsabilidades assumidas pelos pais na medida em que o bebê se desenvolve. Anais $28^{\underline{a}}$ Jornada Acadêmica Integrada. Universidade Federal de Santa Maria, Santa Maria, RS.

Stake, R. E. (1994). Case Studies. In Denzin, N. \& Lincoln, Y. (Coord.). Handbook of Qualitative Research. London: Sage, 236-247.

Staudt, A. C. P. \& Wagner, A. (2009). Paternidade em tempos de mudança. Psicologia: Teoria e Prática, 10(1), 174-185. Recuperado de $<$ http://pepsic.bvsalud.org/scielo.php?script=sci_arttext\&pid=S1516-36872008000100013\&lng=pt\& tlng=pt>.

Strauss, A. \& Corbin, J. (2008). Pesquisa qualitativa: técnicas e procedimentos para o desenvolvimento da teoria fundamentada ( $2^{\underline{a}}$ ed.). Trad. de Rocha, L. O. Porto Alegre: Artes Médicas.

Sutter, C. \& Bucher-Maluschke, J. S. N. F. (2008). Pais que cuidam dos filhos: a vivência masculina na paternidade participativa. Psico, 39(1), 74-82. Recuperado de <http://revistaseletronicas.pucrs.br/ojs/index.php/revistapsico/ article/viewFile/1488/2799>.

Venturini, A. P. C. \& Piccinini, C. A. (2014). Percepção de adolescentes não-pais sobre projetos de vida e sobre a paternidade adolescente. Psicologia \& Sociedade, 26, 172-182. http://dx.doi.org/10.1590/S0102-71822014000500018

Vieira, G. T. \& Nascimento, A. R. A. (2014). Aspectos psicossociais da construção da identidade paterna. Psicologia: Teoria e Prática, 16(1), 57-68. http://dx.doi.org/10.15348/1980-6906/psicologia.v16n1p57-68

Vieira, M. L., Bossardi, C. N., Gomes, L. B., Bolze, S. D., Crepaldi, M. A., \& Piccinini, C. A. (2014). Paternidade no Brasil: revisão sistemática de artigos empíricos. Arquivos Brasileiros de Psicologia, 66(2), 36-52. Recuperado em 28 de outubro de 2014, de <http://seer.psicologia.ufrj.br/index.php/abp/article/view/854>.

\footnotetext{
Autores:

Danielle da Costa Souto - Mestrado, Universidade Federal de Santa Maria.

TATIANE CAPPELARI SilveIRA - Graduado, Centro Universitário Franciscano

MEIRIDIANe Domingues de Deus - Mestrando, Universidade Federal de Santa Maria

MÁRCIA EliSA JAGER - Mestrado, Universidade Federal de Santa Maria

ANA CRISTINA Garcia Dias - Doutorado, Universidade Federal de Santa Maria
}

Endereço para correspondência:

Danielle da Costa Souto

Rua Dom Marcos Teixeira, 240 - Bairro São José (Camobi)

CEP 97095-430 Santa Maria, RS, Brasil

Recebido em: 17.07.14

Aceito em: 24.11.14 